at $1,623 \mathrm{~cm}^{-1}$ is present in both gypsum and hernihydrate and is assigned to the $v_{2}$ mode of $\mathrm{H}_{2} \mathrm{O}$. These frequencies are absent in both soluble and insoluble anhydrite.

The frequencies due to the $\mathrm{SO}_{4}$ group are again different and are important in distinguishing gypsum and all three types of dehydration products. The $v_{1}$ frequency is found at $1,004 \mathrm{~cm}^{-1}$ in gypsum, which is very weak in intensity, whereas it is stronger in hemihydrate and shifts to 1,008 $\mathrm{cm}^{-1}$; again this frequency is very weak in both the soluble and insoluble forms of anhydrite and moves further to $1,012 \mathrm{~cm}^{-1}$ in insoluble anhydrite. The $v_{3}$ vibrations expected at about $1,120 \mathrm{~cm}^{-1}$ show different structures in the different compounds. The $v_{4}$ vibration at $667 \mathrm{~cm}^{-1}$ in gypsum, $660 \mathrm{~cm}^{-1}$ in hemihydrate, 665 $\mathrm{cm}^{-1}$ in soluble anhydrite and $673 \mathrm{~cm}^{-1}$ in insoluble anhydrite could also prove of use in analytical work.

Table 1. DATA ON INFRARED BaNDS OF varIots MODIFICATIONS OF

\begin{tabular}{|c|c|c|c|c|}
\hline Gypsum & Hemihydrate & $\begin{array}{c}\text { Soluble } \\
\text { anhydrite }\end{array}$ & $\begin{array}{l}\text { Insoluble } \\
\text { anhydrite }\end{array}$ & Assignment \\
\hline $\begin{array}{l}667 \mathrm{~s} \\
672 \mathrm{sh}\end{array}$ & $\begin{array}{l}660 \mathrm{~s} \\
670 \mathrm{sh}\end{array}$ & $\begin{array}{l}665 \mathrm{~s} \\
672 \mathrm{sh}\end{array}$ & $\begin{array}{l}666 \mathrm{sh} \\
673 \mathrm{~s}\end{array}$ & $\begin{array}{l}v_{4}, \mathrm{SO}_{4} \\
v_{4}, \mathrm{SO}_{4}\end{array}$ \\
\hline 1004 vw & $1008 \mathrm{~m}$ & $\begin{array}{l}1008 \mathrm{vw} \\
1012 \mathrm{vw}\end{array}$ & $1012 \mathrm{vw}$ & $\begin{array}{l}v_{1}, \mathrm{SO}_{4} \\
v_{1}, \mathrm{SO}_{4}\end{array}$ \\
\hline $\begin{array}{l}1120 \mathrm{vs} \\
1145 \mathrm{vs} \\
1155 \mathrm{sh}\end{array}$ & $\begin{array}{l}1094 \mathrm{~s} \\
1115 \mathrm{~s} \\
1135 \mathrm{sh} \\
1155 \mathrm{vs} \\
1168 \mathrm{sh}\end{array}$ & $\begin{array}{l}1092 \mathrm{~s} \\
1115 \mathrm{~s} \\
1135 \mathrm{sh} \\
1155 \mathrm{vs} \\
1168 \mathrm{sh}\end{array}$ & $\begin{array}{l}1095 \mathrm{~s}(\mathrm{n}) \\
1130 \mathrm{~s}(\mathrm{~d}) \\
1158 \mathrm{vs}\end{array}$ & $\begin{array}{l}v_{s}, \mathrm{SO}_{4} \\
v_{3}, \mathrm{SO}_{4} \\
v_{3}, \mathrm{SO}_{4} \\
v_{8}, \mathrm{SO}_{4} \\
v_{3}, \mathrm{SO}_{4}\end{array}$ \\
\hline$\left\{\begin{array}{l}1617 \mathrm{sh} \\
1623 \mathrm{~s} \\
1688 \mathrm{~m}\end{array}\right.$ & $\left\{\begin{array}{l}1617 \mathrm{sh} \\
1623 \mathrm{~s}\end{array}\right.$ & & & $\begin{array}{l}y_{2}, \mathrm{H}_{2} \mathrm{O} \\
v_{2}, \mathrm{H}_{2} \mathrm{O}\end{array}$ \\
\hline $\begin{array}{l}2130 w \\
2230 w\end{array}$ & $\begin{array}{l}2030 \mathrm{vw} \\
2090 \mathrm{vw} \\
2130 \mathrm{w} \\
2220 \mathrm{vw}\end{array}$ & $\begin{array}{l}2130 \mathrm{vw} \\
2150 \mathrm{vw} \\
2230 \mathrm{vw}\end{array}$ & $\begin{array}{l}2130 \mathrm{vw} \\
2230 \mathrm{vw}\end{array}$ & $\begin{array}{c}2 \times v_{1}, \mathrm{SO}_{4} \\
v_{1}+v_{3}, \mathrm{SO}_{4} \\
v_{2}+v_{3}, \mathrm{SO}_{4} \\
v_{1}+v_{3}, \mathrm{SO}_{4} \\
2 \times v_{3}, \mathrm{SO}_{4}\end{array}$ \\
\hline $\begin{array}{l}3245 \mathrm{sh} \\
3410 \mathrm{~s} \\
3500 \mathrm{w} \\
3555 \mathrm{~m}\end{array}$ & $\begin{array}{l}3560 \mathrm{~m} \\
3615 \mathrm{~s}\end{array}$ & & & $\begin{array}{l}2 \times v_{2}, \mathrm{H}_{2} \mathrm{O} \\
2 \times v_{3}, \mathrm{H}_{2} \mathrm{O} ; v_{3}, \mathrm{H}_{2} \mathrm{O} \\
v_{1}, \mathrm{H}_{2} \mathrm{O} \\
v_{1}, \mathrm{H}_{2} \mathrm{O} \\
v_{3}, \mathrm{H}_{2} \mathrm{O}\end{array}$ \\
\hline
\end{tabular}

n, Only obtained with Nujol mull; d, only obtained with $\mathrm{KBr}$ disk; rw, very weak; $w$, weak; m, medium; s, strong; vs, very strong; sh, shoulder.

These studies have confirmed the existence of only three different products on thermal dehydration of $\mathrm{CaSO}_{4}, 2 \mathrm{H}_{2} \mathrm{O}$. No spectral differences have been obtained between the socalled $\alpha$ and $\beta$ forms of hemihydrate or soluble anhydrite. The latter compound is very susceptible to moisture and quickly converts to hemihydrate when exposed to the atmosphere. The insoluble anhydrite is a stable form, and the total conversion from gypsum and its other dehydration products to this form only seems to take place at temperatures above $400^{\circ} \mathrm{C}$.

We thank Mr T. Smallwood for performing the TGA and $\mathrm{Mr} \mathrm{G}$. Dance for the $\mathrm{X}$-ray diffraction measurements.

John Bensted

Satya Prakash

Associated Portland Cement Manufacturers Ltd,

Research Laboratories,

Greenhithe,

Kent.

Received April 23, 1968.

${ }^{1}$ Weiser, H. B., Milligan, W. O., and Ekholm, W. C., J. Amer. Chem. Soc., 58, 1261 (1936).

${ }^{2}$ Kelley, K. K., Southard, J. C., and Anderson, C. T., US Bureau of Mines Tech. Paper, 625 (1941).

'Gilliland, J. L., Proc. Amer. Concrete Inst., 47, 809 (1951).

' Flörke, O. W., Neues Jahrbuch für Miner, Abh., 84 (2), 189 (1952).

${ }^{5}$ Mtschedlow-Petrossian, O. P., and Berschadski, F. G., Silikattechnik, 18 (5), 147 (1967).

- Hunt, J. M., Wisherd, M. P., and Bonham, L. C., Anal. Chem., 22, 1478 $1950)$

2 Miller, F.A., and Wilkins, C. H. Anal Chem, 24, 1253 (1952)

'Hass, M., and Sutherland, G. B. B. M., Proc. Roy. Soc., A, 236, 427 (1956).

- Pain, C., Duval, C., and Lecompte, J., CR Acad. Sci., 23\%, 238 (1953).

\section{How Inaccurate is Pauling's Bond Energy Equation?}

Pearson ${ }^{1}$ recently pointed out that Pauling's bond energy equation does not give reasonable values of the enthalpy changes for a series of reactions, and he has also stressed a number of pitfalls of Pauling's electronegativities. The principle of soft and hard acids and bases (SHAB), on the other hand, predicts the correct sign of $\Delta H$ for those reactions and the general chemical patterns mishandled by the simple electronegativity concept.

It is well known that Pauling's equation is only moderately successful. For forty-two bonds listed by Pauling?, the average overall agreement is \pm 20 per cent; for five of these bonds $(\mathrm{P}-\mathrm{H}, \mathrm{H}-\mathrm{F}, \mathrm{Si}-\mathrm{O}, \mathrm{C}-\mathrm{I}, \mathrm{Cl}-\mathrm{F})$, it is only \pm 40 per cent. A detailed analysis ${ }^{3}$ of Pauling's electronegativity scale shows that it has no rigorous quantum mechanical basis and that it must be considered as a useful empirical generalization. I wish to point out, however, that Pearson's examples focus on the most serious limitations of Pauling's equation First, Pauling has stated ${ }^{4}$ that his equation gives very poor results if $\left(X_{A}-X_{B}\right)>1 \cdot 5$, and no ionic bonds are included in his list. This is confirmed by the examination of its fragile valence bond or molecular orbital basis ${ }^{3,5,6}$. Second, Pauling uses average bond energies, $\bar{E}_{A B}=(1 / n)$ $\Delta H_{\text {at }}$, where $\Delta H_{\text {at }}$ is the heat of atomization of species $A B_{n}$. Of the eighteen $\Delta H$ values discussed by Pearson ${ }^{1}$, seven involve the breaking and formation of highly ionic bonds, and nine others correspond to reactions in which a particular bond or bonds in polyatomic molecules are being broken and/or formed. Third, errors of 20 per cent in bond energies will be much greater in reactions such as

$$
A-B+C-D \rightarrow A-D+B-C
$$

where differences are taken (personal communication). As a result, it is not surprising that Pauling's equation fails signally for the chosen examples.

Indeed, it is impossible to expect that any bond energy equation based on atomic parameters, be they electronegativities or soft-hardness, can work well in all or even most cases. Interatomic terms are always present and are the dominant factors in all bonding theories. In LCAO-MO methods these terms are the exchange integrals (important in essentially covalent bonds) and the interatomic electrostatic terms (Madelung-Jørgensen energies) of the Coulomb integrals (important in highly ionic com pounds). If these terms are introduced in a simple approximation involving electronegativities? ${ }^{7}$ the correct values for the enthalpy changes of processes like reaction (4) of the paper by Pearson

$$
\mathrm{LiF}(\mathrm{g})+\mathrm{CsI}(\mathrm{g})=\mathrm{LiI}(\mathrm{g})+\operatorname{CsF}(\mathrm{g})
$$

are obtained, as well as the correct behaviour in the case of many of the pitfalls mentioned by Pearson.

\section{Ricardo Ferreira}

Department of Chemistry,

Earlham College,

Richmond,

Indiana.

Received May 31, 1968.

1 Pearson, R. G., Chem. Commun., 2, 65 (1968).

sauling, L., The Nature of the Chemical Bond, third ed., 90 (Cornell University Press, 1960).

${ }^{3}$ Ferreira, R., Adv. Chem. Phys., 13, 55 (1967).

'Pauling, L., The Nature of the Chemical Bond, second ed,, 61 (Cornell University Press, 1940).

${ }^{5}$ Mulliken, R. S., J. Chem. Phys., 3, 573 (1935).

'Pearson, R. G., J. Chem. Phys., 17, 969 (1949).

? Hofer, O., and Ferreira, R., J. Phys. Chem.. 70. 85 (1966). 